\title{
Premedication with gabapentin for laryngoscopy: a double-blind randomized control trial in hypertensive patients
}

\author{
Muhammad Imran Riasat, FCPS ${ }^{1}$, Haris Tariq Chohan, FCPS ${ }^{1}$, Arun Kumar, FCPS ${ }^{1}$, Syed Farjad
} Sultan, FCARCSI, PhD ${ }^{2}$, Hanya Javaid, MBBS ${ }^{3}$, Safia Zafar Siddiqui FCPS, MSc (Pain Medicine) ${ }^{4}$ Authors' affiliations:

1- Senior Registrar, Department of Anesthesiology, SICU \& Pain Management, Dr. Ruth K.M. Pfau Civil Hospital, Karachi, Pakistan.

2- Assistant Professor, Department of Anesthesiology, SICU \& Pain Management, Dr. Ruth K.M. Pfau Civil Hospital, Karachi, Pakistan.

3- Anesthesia Resident, Department of Anesthesiology, SICU \& Pain Management, Dr. Ruth K.M. Pfau Civil Hospital, Karachi, Pakistan.

4- Professor and Head, Department of Anesthesiology, SICU \& Pain Management, Dr. Ruth K.M. Pfau Civil Hospital, Karachi, Pakistan.

Correspondence: Dr. Muhammad Imran Riasat, FCPS, Department of Anesthesiology, SICU and Pain Management, Dr. Ruth K.M Pfau Civil Hospital Karachi, Baba-e-Urdu Road, Karachi, Pakistan; Phone: +92-334-2947181; E-mail: dr.imranriasat@gmail.com

\section{Abstract}

Background \& Objective: Laryngoscopy and intubation (L\&I) are strong stimulus for cardiovascular system. Hypertensive patients have a greater incidence of coexisting coronary artery disease and cerebrovascular insufficiency. Several methods have been in practice to prevent or alter the hemodynamic response to L\&I. Although the main use of gabapentin has been as an antiepileptic, but its effect on the hemodynamic reflexes is still under evaluation. We compared the effectiveness of a single dose of gabapentin $800 \mathrm{mg}$ on the mean arterial pressure (MAP) in response to L\&I in hypertensive patients undergoing day care surgery.

Methodology: This randomized, control trial was conducted in operating rooms, Dr Ruth K M Pfau Civil Hospital Karachi, from May 2017 to November 2017. A total of 150 patients undergoing elective surgery requiring general anesthesia with tracheal intubation were included in this study. Patients were randomly allocated equally into two group; Group G (gabapentin group) and Group P (placebo group). Patients in Group G received gabapentin $800 \mathrm{mg}$ and Group P received placebo, $2 \mathrm{~h}$ prior to induction of anesthesia. MAP was measured at baseline (before induction), before intubation (after induction), at time 0 (immediately after intubation), and at $1 \mathrm{~min}, 3 \mathrm{~min}, 5 \mathrm{~min}$, and $10 \mathrm{~min}$ after intubation. Effectiveness was defined as all the MAP reading to be within $30 \%$ of the baseline reading.

Results: There were $72(48 \%)$ males and 78(52\%) females. Effectiveness was significantly higher in patients of Group $\mathrm{G}$, as compared to placebo group (Group P) [94.7\% vs. $65.3 \% ; \mathrm{p}=0.0005]$.

Conclusion: Gabapentin effectively suppresses the increase in MAP in response to laryngoscopy and tracheal intubation as compared to the placebo.

Abbreviations: L\&I: Laryngoscopy and intubation; MAP: Mean arterial pressure; ECG: Electrocardiography; ASA: American Society of Anesthesiologists; BMI: Body mass index; SBP: Systolic blood pressure; DBP: Diastolic blood pressure 
Key words: Laryngoscopy; Intubation; Hypertension; Gabapentin; Stress response

Citation: Riasat MI, Chohan HT, Kumar A, Sultan SF, Javaid H, Siddiqui SZ. Premedication with gabapentin for laryngoscopy: a double-blind randomized control trial in hypertensive patients. Anaesth. pain intensive care 2021;25(2):163-169. DOI: 10.35975/apic.v25i2.1464

\section{Introduction}

Laryngoscopy for tracheal intubation (L\&I) is a potent stimulus for sympathetic stimulation. ${ }^{1}$ Hypertensive patients show accentuated pressor response to tracheal intubation and laryngoscopy that can result in life threatening hypertensive crisis. ${ }^{2-5}$

Multiple techniques such as increasing of the depth of anesthesia, avoiding cholinergic premedication, pretreatment with vasodilators such as calcium channel blockers, nitroglycerin, opioids and beta-blockers have been used to prevent the pressor responses following laryngoscopy and intubation. ${ }^{6}$

Gabapentin is a structural analogue of the neurotransmitter, $\gamma$-aminobutyric acid (GABA) that was introduced as an antiepileptic drug. ${ }^{7}$ It has proven its role in managing pain (neuropathic and acute postoperative) and has reduced the postoperative requirement of opioid. ${ }^{8}$

According to the current guide lines, hypertension should not lead to deferring or cancellation of surgery unless it is hypertensive crisis. ${ }^{9,10}$ Although, Gabapentin is effective in attenuating in hemodynamic response to L\&I in individuals without any significant coexisting diseases, ${ }^{11}$ little is known about hypertensives. So, our rationale was to see the effect of gabapentin in controlled hypertensive patients who were undergoing elective day-care procedures and have missed their morning antihypertensive medication dose.

Objective: To compare the effectiveness of a single dose gabapentin $800 \mathrm{mg}$ on the mean arterial pressure (MAP) in response to L\&I in hypertensive patients undergoing day care surgery.

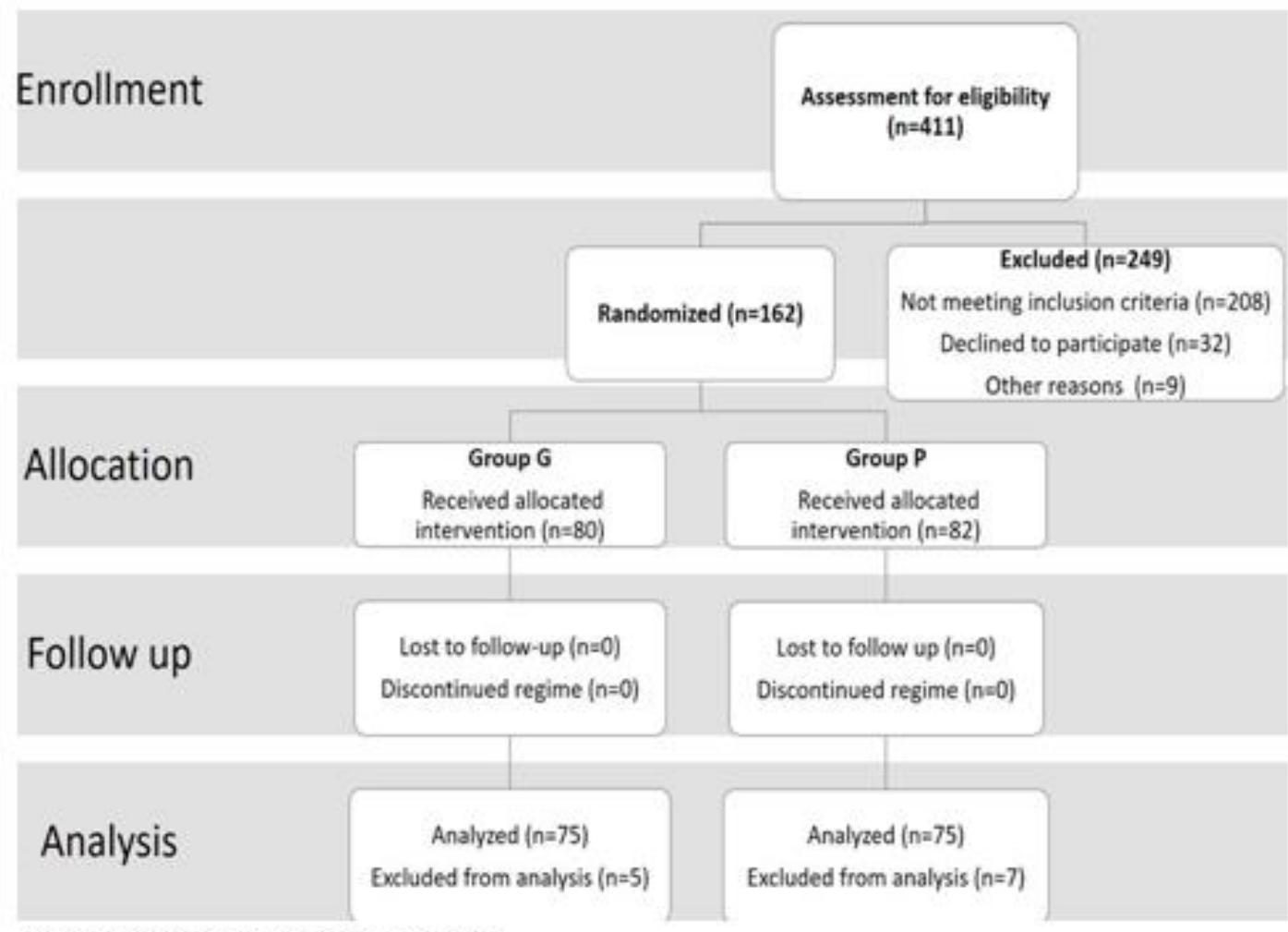

Figure 1: CONSORT Flow Chart 


\section{Research Methodology}

This study was conducted at the Department of Anesthesiology, Dr. Ruth K. M. Pfau Civil Hospital Karachi, from May 2017 to November 2017. After obtaining approval from hospital ethical board and written informed consent, 150 known hypertensive patients were included. Hypertensives (35-60 y of age) who had missed their morning antihypertensive medication and were undergoing day-care surgery requiring general anesthesia with L\&I were randomized to either gabapentin or control group. Patients with anticipated difficult intubation (grade 3 and 4 according to mallampati), having high risk of aspiration (known cases of hiatus hernia, and acid reflux disease), obesity (BMI > $30 \mathrm{~kg} / \mathrm{m} 2$ ), any previous history of ischemic heart disease, arrhythmias, cerebrovascular disease and those who had taken their morning antihypertensive medications were excluded.

Eligible patients were randomized into one of the two groups through randomization.com. Group $\mathrm{G}$ included patients who received oral gabapentin $800 \mathrm{mg}$ and Group P received a placebo (empty capsule). Both the drugs were in form of capsules and were labelled study drug and were given a serial number in pharmacy of our hospital and then were sent to preoperative assessment area. The anesthesiologists of the preoperative clinic were instructed to give the study drug with a sip of water $2 \mathrm{~h}$ prior to surgery. Standard monitoring with pulse oximeter, non-invasive blood pressure (NIBP), electrocardiography (ECG), endtidal concentration of carbon dioxide was done intraoperatively for every patient by a consultant anesthesiologist (having 5 or more years of experience).

Propofol $1 \mathrm{mg} / \mathrm{kg}$ and nalbuphine $0.1 \mathrm{mg} / \mathrm{kg}$ were used for induction followed by atracurium $0.5 \mathrm{mg} / \mathrm{kg}$, then anesthesia was maintained with $40 \%$ oxygen with 1.2 volume $\%$ isoflurane. Nerve stimulator was used and endotracheal tube was placed when the train of four counts reached zero. If more than two attempts were made for laryngoscopy or the intubation tool more than 2 min the data was noted and the patient was excluded from the study.

Heart rate (HR), blood pressure (BP) and electrocardiograph were recorded as baseline (before induction), before intubation (after induction), at time
0 (immediately after intubation), and at $1 \mathrm{~min}, 3 \mathrm{~min}$, $5 \mathrm{~min}$, and $10 \mathrm{~min}$ after intubation MAP was noted. As the exact thresholds of $\mathrm{BP}$ are undefined ${ }^{12}$ and change of MAP of more than $30 \%$ was associated with a poor outcome $^{13}$ so, effectiveness was labelled when all the reading were within $30 \%$ of baseline.

Hypotension [mean arterial pressure less than 65 $\mathrm{mmHg}$ or more than $30 \%$ decrease from baseline lasting for less than one minute] (which might occur as a side effect of IV induction agent, inhalation agent or our study drug) was managed with intravenous fluid or boluses of $50 \mu \mathrm{g}$ of phenylephrine; atropine was used to manage bradycardia (HR $<40 / \mathrm{min}$ ).

Tachycardia (HR $>120$ beats/min or $>30 \%$ increase from baseline lasting for $>1 \mathrm{~min}$ ) or hypertension (DBP > $110 \mathrm{mmHg}$ or SBP $>180 \mathrm{mmHg}$ or $>30 \%$ increase from baseline lasting for more than $1 \mathrm{~min}$ ). Isoflurane concentration was increased if the drug was ineffective and further management was as per the anesthesiologist's clinical practice. This information, along with age, sex, ASA status, height and weight, was noted.

Statistical analysis: Statistical Package for Social Science (v.20, SPSS Inc., Chicago, IL, USA) was used to analyze data. Frequencies and percentages were computed for categorical variables like ASA status, sex, effectiveness. Mean and standard deviation was computed for quantitative variables like age, duration of hypertension, duration of treatment of hypertension, BMI, SBP, DBP and MAP. The groups were compared in terms of efficacy, applying chi square test.

Stratification of age, BMI, ASA status, sex and duration of treatment of hypertension was done to control these effect modifiers on outcome variables. $\mathrm{P}$ $\leq 0.05$ was considered as significant.

\section{Results}

A total of 162 patients were recruited for our study, while 150 patients completed it and were analyzed for effectiveness (as shown in Figure 1). The average age of the patients was $44.32 \pm 7.57 \mathrm{y}$ and $43.40 \pm 6.83 \mathrm{y}$ in group $\mathrm{P}$ and Group $\mathrm{G}$ respectively. There were $72(48 \%)$ males and $78(52 \%)$ females.

Effectiveness of gabapentin $800 \mathrm{mg}$ was significantly high as compared to placebo [94.7\% vs. $65.3 \%$; $\mathrm{p}=$ 0.0005] as shown in Table 1. 
Table 1: Comparative effectiveness between two groups

\begin{tabular}{l|l|l|l|l}
\hline Effectiveness & $\begin{array}{l}\text { Group P } \\
\text { N=75 }\end{array}$ & $\begin{array}{l}\text { Group G } \\
\text { N=75 }\end{array}$ & Total & p-value \\
\cline { 1 - 4 } $\begin{array}{l}\text { Yes } \\
\text { [MAP within } 30 \% \text { from baseline] }\end{array}$ & $29(65.3 \%)$ & $71(94.7 \%)$ & $120(80 \%)$ & 0.0005 \\
\cline { 1 - 3 } $\begin{array}{l}\text { No } \\
\text { [change of } M A P>30 \% \text { from base/ine] }\end{array}$ & $26(34.7 \%)$ & $4(5.3 \%)$ & $30(20 \%)$ & \\
\hline Chi-square $=20.167$ & & & & \\
\hline
\end{tabular}

Age was stratified in three groups and observed the effect of age on efficacy; however, effectiveness of Group $\mathrm{G}$ was significantly high in $\leq 40$ and 41 to $50 \mathrm{y}$ of age except above $50 \mathrm{y}$ of age. It was statistically more significant in females $(p=0.0005)$. Similarly, effectiveness was also high in groups $G$ after to the ones with pre-existing hypertension or other past medical conditions, such as myocardial infarction or cerebrovascular disease. It is, therefore, of prime importance to prevent the likely hemodynamic changes following tracheal intubation in hypertensive patients. ${ }^{15}$

Attenuation of hemodynamic stress response to L\&I in normotensive patients has been documented in various studies in the literature. A study by Serhat Koc et al. compared $400 \mathrm{mg}$ and $800 \mathrm{mg}$ of gabapentin, and they reported that the lower dose was ineffective in

Table 2: Effectiveness according to different variables

\begin{tabular}{|c|c|c|c|c|c|}
\hline Variables & $\begin{array}{l}\text { Total } \\
\text { patients } \\
\text { (n) }\end{array}$ & $\begin{array}{l}\text { Total } \\
\text { Effective } \\
\text { (E) }\end{array}$ & $\begin{array}{l}\text { Group P } \\
\text { E/n (\%) }\end{array}$ & $\begin{array}{l}\text { Group G } \\
\text { E/n (\%) }\end{array}$ & p-value \\
\hline \multicolumn{6}{|l|}{ Age (Y) } \\
\hline$\leq 40$ & 65 & 50 & $18 / 30(60 \%)$ & $32 / 35(91.4 \%)$ & 0.003 \\
\hline $41-50$ & 52 & 44 & $19 / 27(70.4 \%)$ & $25 / 25(100 \%)$ & 0.003 \\
\hline$>50$ & 33 & 26 & $12 / 18(66.7 \%)$ & $14 / 15(93.3 \%)$ & 0.095 \\
\hline \multicolumn{6}{|l|}{ Gender } \\
\hline Male & 72 & 60 & $21 / 29(72.4 \%)$ & $39 / 43(90.7 \%)$ & 0.041 \\
\hline Female & 78 & 60 & $28 / 46(60.9 \%)$ & $32 / 32(100 \%)$ & 0.0005 \\
\hline \multicolumn{6}{|c|}{$\mathrm{BMI}\left(\mathrm{kg} / \mathrm{m}^{2}\right)$} \\
\hline$\leq 25$ & 96 & 83 & $33 / 43(76.7 \%)$ & $50 / 53(94.3 \%)$ & 0.012 \\
\hline $25.1-29.9$ & 40 & 27 & $12 / 24(50 \%)$ & $15 / 16(93.8 \%)$ & 0.004 \\
\hline $30-35$ & 14 & 10 & $4 / 8(50 \%)$ & $6 / 6(100 \%$ & 0.085 \\
\hline \multicolumn{6}{|c|}{ Duration of treatment of hypertension (Y) } \\
\hline$<10$ & 54 & 46 & $22 / 29(75.9 \%)$ & $24 / 25(96 \%)$ & 0.038 \\
\hline$>10$ & 96 & 74 & $27 / 46(58.7 \%)$ & $47 / 50(94 \%)$ & 0.0005 \\
\hline
\end{tabular}

stratification of BMI and duration of hypertension of treatment. (Table 2)

\section{Discussion}

Laryngoscopy and tracheal intubation result in marked stress response that manifests itself in the form of changes in HR, BP and arrthymias. ${ }^{14}$ These temporary responses have no dire consequence in healthy individuals but may be dangerous and life threatening preventing pressor response after tracheal intubation. ${ }^{16}$

There is scarcity of data regarding the evaluation of the effect of gabapentin pre-treatment on L\&I in patients with hypertension. One such study conducted by Bala et al. by using $800 \mathrm{mg}$ gabapentin on controlled hypertensives showed similar results as our study, ${ }^{17}$ despite the fact that we only included those who had missed their antihypertensive medication because of the overnight fasting instructions. This finding may 


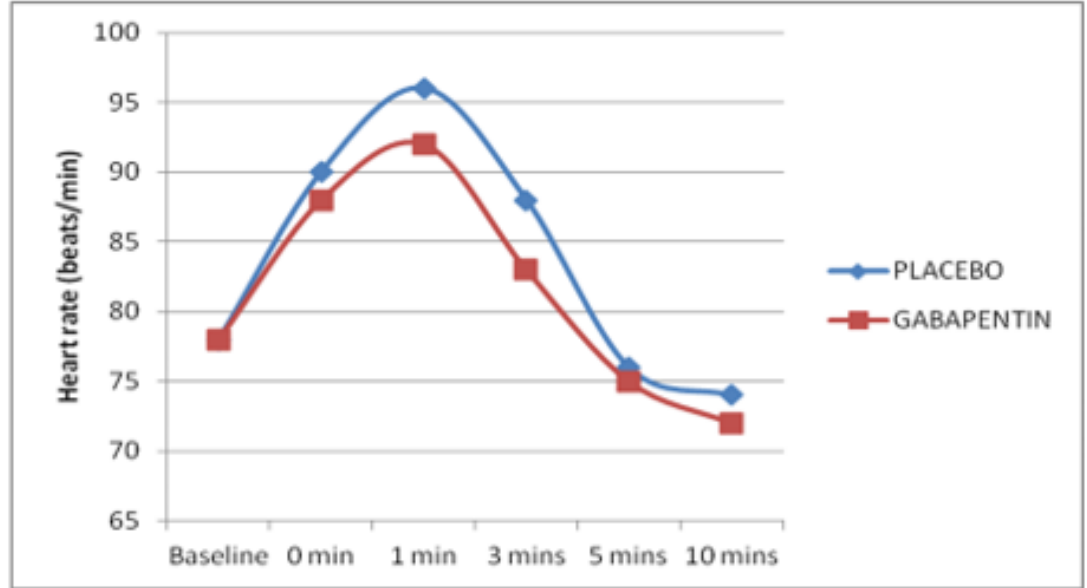

Figure 2: Comparative effect on heart rate in two groups

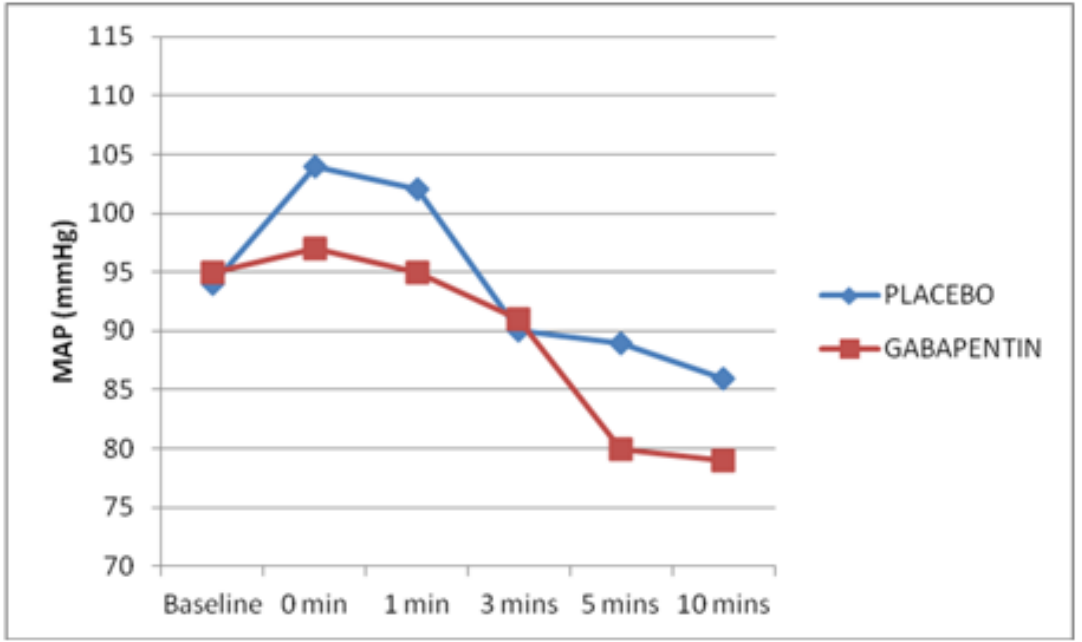

Figure 3: Comparative effect on MAP in two groups

prove beneficial in non-compliant hypertensive patients who might otherwise have their procedures postponed.

In contrast to our study, another study was conducted by Farzi et al. ${ }^{18}$ in patients undergoing septorhinoplasty. They used $900 \mathrm{mg}$ gabapentin and did not find a significant effect on the hemodynamic changes induced by laryngoscopy except for SBP. It could be because of the difference in time intervals taken to measure BP. We found the maximum attenuation just after intubation and at one minute after that, while their first measurement was taken at $3 \mathrm{~min}$ after induction. The other consideration could be the procedure of septorhinoplasty itself, as the procedure normally involves infiltration of local anesthetic and vasoconstricting agent which may have contributed to their findings.

When compared with other standard agents such as lidocaine or fentanyl, gabapentin was inferior for many hemodynamic outcomes. ${ }^{19,20}$ But in our country, the high cost and the availability of fentanyl and clonidine is a serious problem. On the other hand, gabapentin is easily available and relatively cheap. Despite the fact that clonidine and beta blockers have manifested promising results in reducing perioperative cardiac effects, ${ }^{21}$ a higher incidence of clinically significant hypotension and cardiac arrest were noted with clonidine, but no evidence of refractory hypotension or ischemic changes were noted with gabapentin. $^{22}$

A meta-analysis conducted by Doleman B. et al. concluded the effectiveness of gabapentin in attenuating the pressor responses following intubation when compared with the control group. ${ }^{23}$

The strength of our study was double blinded randomization on specific sub-group of hypertensive

patients.

\section{Limitations}

Our study had certain limitations. Firstly, the patients included in our study were on various antihypertensive drugs which included beta blockers that could also have affected the hemodynamics. Even though, there are studies which show no additional benefits from bispectral index (BIS) monitoring, ${ }^{24}$ lack of depth of anesthesia monitoring could lead to increased awareness and pain, and effect the hemodynamic parameters.

The other limitations included overlooking the incidence of postoperative sedation, postoperative hypotension and pain scores. 
Hemodynamic responses in hypertensive patients are not only seen in response to L\&I, but other intraoperative factors could also give rise to these variations. Such as, intra-abdominal hypertension caused by gas insufflation in laparoscopic procedures. Future studies could be done keeping these factors in mind.

\section{Conclusion}

We conclude that $800 \mathrm{mg}$ gabapentin is an effective drug in attenuating the cardiovascular pressor response to laryngoscopy and tracheal intubation in hypertensive patients.

\section{Conflict of interests}

No conflict declared by the authors. No funding or grant was involved in the conduct of this study.

\section{Authors' contribution}

MIR: Concept, design of study

HTC: Acquisition \& analysis

AK: Interpretation \& manuscript drafting

SFS: Overlooked all study work, and accuracy of study

HJ: Drafting and revising critical content

SZS: Overall supervision

\section{References}

1. Suryawanshi CM, Kumar R, Wadhwa R. A prospective study comparing the efficacy of intravenous clonidine with intravenous dexmedetomidine in attenuating the hemodynamic stress response during laryngoscopy and endotracheal intubation. Indian Journal of Clinical Anesthesia. $2018 \mathrm{Jul} ; 5(3): 327-33$. DOI: 10.18231/23944994.2018.0063

2. Swami NR, Badhe VK, Deshpande VV, Badhe VK, Shidhaye RV. A comparison between intravenous metoprolol and labetalol in prevention of cardiovascular stress response to laryngoscopy and intubation. Anaesth Pain Intensive Care. 2018;22(2):180-186. [FreeFullText]

3. Hegazy AA, Abd El-Aziz AF. Comparative study between Macintosh versus C-MAC laryngoscopic performance in airway management with dexmedetomidine as stress response attenuator in obese patients. Ain-Shams J Anaesthesiol. 2017;10(1):117-23. [FreeFullText]

4. Dhanya PR, Franklin D. Effect of Oral Pregabalin on Hemodynamic Stress Response to Laryngoscopy and Endotracheal intubation. J Med Sci Clin Res. 2017;5(4):20678-84. DOI:10.18535/jmscr/v5i4.153
5. Tahir MS, Khan NA, Masood M, Yousaf M, Warris SA. Comparison of pressor responses following laryngeal mask airway vs. laryngoscopy and endotracheal tube insertion. Anaesth Pain Intensive Care. 2008; 12:11-5. [FreeFullText]

6. Fasoulaki A, Melemeni A, ParaskevaA, Petropoulos G Gabapentin attenuates the pressor response to direct laryngoscopy and tracheal intubation. $\mathrm{Br} \mathrm{J}$ Anaesth. 2006;96(6):769-73. [PubMed] DOI: 10.1093/bja/ael076

7. Basuroy K, Kantharaju K, Aravinda S, Shamala N, Balaram P. Pregabalin peptides: conformational comparison of $y$ 3-and $y$ 4-substituted $y$-amino acids in ayaaa pentapeptides. Amino acids. 2019 Sep 1;51(9):1297-306. [PubMed] DOI: 10.1007/s00726-019$\underline{02768-5}$

8. Arumugam S, Lau CS, Chamberlain RS. Use of preoperative gabapentin significantly reduces postoperative opioid consumption: a meta-analysis. J Pain Res. 2016 Sep 12:9:631-40. [PubMed] DOI: 10.2147/JPR.S112626

9. Kristensen SD, Knuuti J, Saraste A, Anker S, Bøtker HE, De Hert S, et al. 2014 ESC/ESA guidelines on noncardiac surgery: cardiovascular assessment and management: the Joint Task Force on non-cardiac surgery: cardiovascular assessment and management of the European Society of Cardiology (ESC) and the European Society of Anaesthesiology (ESA) Eur Heart J. 2014;35:2383-2431. [PubMed] DOI: 10.1097/EJA.0000000000000150

10. Fleisher LA, Fleischmann KE, Auerbach AD, Barnason SA, Beckman JA, Bozkurt B, et al. 2014 ACC/AHA guideline on perioperative cardiovascular evaluation and management of patients undergoing noncardiac surgery: a report of the American College of Cardiology/American Heart Association Task Force on practice guidelines. J Am Coll Cardiol. 2014;64: e77137. [PubMed] DOI: $10.1016 / j . j a c c .2014 .07 .944$

11. Yaqoob S, Gani TT, Mir AH, Yousuf A, Mir AW, Khaliq S. A comparative randomized study to evaluate the effect of gabapentin alone and in combination with labetalol in attenuating the pressor response to direct laryngoscopy and intubation. Int J Med Sci Public Health 2018;7(1):58-62. [PubMed] DOI: 10.5455/ijmsph.2018.0926825112017

12. Packiasabapathy K S, Subramaniam B. Optimal perioperative blood pressure management. Adv Anesth. 2018 Dec;36(1):67-79. [PubMed] DOI: 10.1016/j.aan.2018.07.003

13. POISE Study Group, Devereaux PJ, Yang H, Yusuf S, Guyatt G, Leslie K, et al. Effects of extended-release metoprolol succinate in patients undergoing non-cardiac surgery (POISE trial): a randomised controlled trial. Lancet. 2008 May 31;371(9627):1839-47. [PubMed] DOI: $10.1016 / \mathrm{S} 0140-6736(08) 60601-7$

14. Sharma R, Singh S, Taank P. Comparison of lignocaine and fentanyl for attenuation of cardiovascular response during laryngoscopy and tracheal intubation in cardiac surgery patients. Int J Biomed Res. 2018;9(10):342-5. [FreeFullText] 
15. Kumar R, Gandhi R, Mallick I, Wadhwa R, Adlakha N, Bose M. Attenuation of hemodynamic response to laryngoscopy and endotracheal intubation with two different doses of labetalol in hypertensive patients. Egyptian Journal of Anaesthesia. $2016 \mathrm{Jul}$ 1;32(3):33944. DOI: 10.1016/j.egja.2016.04.004

16. Koç $S$, Memis D, Sut $N$. The preoperative use of gabapentin, dexamethasone, and their combination in varicocele surgery: a randomized controlled trial. Anesth Analg. 2007 Oct;105(4):1137-42. [PubMed] DOI: $\underline{10.1213 / 01 . a n e .0000278869 .00918 . b 7}$

17. Bala I, Bharti N, Ramesh NP. Effect of gabapentin pretreatment on the hemodynamic response to laryngoscopy and tracheal intubation in treated hypertensive patients. Acta Anaesthesiol Taiwan. 2015 Sep;53(3):95-8. [PubMed] DOI: 10.1016/j.aat.2015.07.004

18. Farzi F, Haddadi S, Ebrahimpour N, Roshan ZA, Habibi $A F$, Mirmansouri A, et al. A survey on the effect of oral gabapentin on hemodynamic changes during direct laryngoscopy and tracheal intubation and intraoperative bleeding in patients undergoing septorhinoplasty. Anesthesiology and pain medicine. 2015 Oct:5(5):e29705. [PubMed] DOI: 10.5812/aapm.29705

19. Kumar A, Seth A, Prakash S, Deganwa M, Gogia AR. Attenuation of the hemodynamic response to laryngoscopy and tracheal intubation with fentanyl, lignocaine nebulization, and a combination of both: A randomized controlled trial. Anesth Essays Res. 2016
Sep-Dec;10(3):661-666. [PubMed] DOI: 10.4103/0259$\underline{1162.191113}$

20. Mahajan A, Gupta AK, Gulati S, Gupta S. Efficacy of intravenous lignocaine $2 \%$ versus oropharyngeal topical $10 \%$ xylocaine spray before induction of anaesthesia in attenuating the pressor response to direct laryngoscopy and endotracheal intubation. JK Sci. 2019;21(1):3-7. [FreeFullText]

21. Waikar C, Singh J, Gupta D, Agrawal A. Comparative study of oral gabapentin, pregabalin, and clonidine as premedication for anxiolysis, sedation, and attenuation of pressor response to endotracheal intubation. Anesth Essays Res. 2017 Jul-Sep;11(3):558-560. [PubMed] DOI: 10.4103/aer.AER_34_17

22. Nanda A, Krishnamurthy D, Madhusudhana R, Potli S. Comparative study of clonidine and gabapentin for attenuating hemodynamic responses to laryngoscopy and tracheal intubation. IOSR J Dent Med Sci. 2015; 14:110-7. [FreeFullText]

23. Doleman B, Sherwin M, Lund JN, Williams JP. Gabapentin for the hemodynamic response to intubation: systematic review and meta-analysis. Can J Anaesth. 2016 Sep;63(9):1042-58. [PubMed] DOI: 10.1007/s12630-016-0668-0

24. Avidan MS, Zhang L, Burnside BA, Finkel KJ, Searleman AC, Selvidge JA, et al. Anesthesia awareness and the bispectral index. N Engl J Med. 2008 Mar 13;358(11):1097-108. [PubMed] DOI: 10.1056/NEJMoa0707361 